\title{
Evaluation of heavy-duty vehicles engine life with controlled modification of engine oil
}

\author{
Anton Shalkov ${ }^{1 *}$, Andrey Kuznetsov ${ }^{1}$, and Evgeny Kuzin ${ }^{1}$ \\ ${ }^{1}$ T.F. Gorbachev Kuzbass State Technical University, Branch of Prokopievsk, 653039, 19a \\ Nogradskaya str., Prokopievsk, Kemerovo region, Russian Federation
}

\begin{abstract}
The article presents the method of controlled modification of engine oil, as well as the results of operational studies to assess the service life of heavy-duty vehicle engines. The method of controlled modification of engine oil includes a system of five levels of information helping to assess the technical condition of engines of heavy-duty vehicles, including mining dump trucks. The first level of the methodology includes the use of subjective methods for determining the technical condition of engines by its external manifestations. The second level of the methodology includes the use of simple instrumental methods and means of obtaining diagnostic information about the technical condition of the engine and its subsystems. The third level of the technique involves the use of a drip test of engine oil. The fourth level of the methodology includes the chemical analysis of engine oil samples. The fifth level of the technique involves spectral analysis of engine oil to determine the presence of metals.
\end{abstract}

\section{Introduction}

Practical data show that in order to reliably determine and maximize the use of the assigned resource of mining machines, including car engine parts, it is necessary to constantly monitor their wearing process $[1,2]$. This can be achieved by using the method of controlled modification of engine oil. There are a large number of different methods for improving the performance of friction pairs [3-7]. However, it seems economically feasible to add additives to the lubricating oil for effective improvent of the performance and extencion of the service life of the friction elements of engines of heavy-duty and quarry cars [8-13]. It is established that the most rational for high-load internal combustion engines is the "Autopreparation "NanoKOR-F", which is based on theoretical and experimental studies.

In this regard, it is advisable to develop a method for controlled modification of engine oil for operational studies of the performance of heavy-duty vehicle engines, on the basis of theoretical and experimental studies.

\footnotetext{
${ }^{*}$ Corresponding author: prk-s @, yandex.ru
} 


\section{Formulation of the problem}

The method of controlled modification of engine oil involves several stages (levels) of sampling of engine oil. The first stage is oil sampling after 100-150 operating hours of heavyduty vehicle engines. The next stage is repeated sampling every 100-110 engine operating hours. Further, if necessary, the engine oil is modified with an additive with the selection of test samples and controlled actions, which are performed to identify the technical condition of the engine oil until it is replaced during maintenance No. 2 (M-2). It can be performed with an analysis of changes in the properties inherent in the used oil to justify the timing of oil change.

Moreover, the method of controlled modification of engine oil includes a system of information support levels for the technical condition of engines. The collection of diagnostic signals with a step-by-step clarification of the causes of failures makes it possible to determine the technical condition of the engines with a high degree of probability. At the same time, the method of controlled modification of engine oil includes the analysis of wear products in the oil (the "drop test" method, chemical analysis, spectrographic), which have proven their effectiveness [14-16].

The first level of the technique of controlled modification of engine oil involves the use of subjective methods for determining the technical condition of engines by its external manifestations. It includes visual inspection, checking for hearing, smell, touch, the correctness of the signal equipment, algorithms for performing technological operations in the whole. In addition, at this level laboratory oil tests are carried out on the indicators that characterize its appearance, density and content of the main elements before the start of the engine operation.

The second level of the methodology includes the use of simple instrumental methods and means of obtaining diagnostic information about the technical condition of the engine and its subsystems. Such devices are stethoscopes, compressometers, crankcase gas volume meters, gas analyzers, engine oil flow meters for carbon monoxide.

The third level of the technique uses the method of a drip sample of engine oil.

The fourth level includes the chemical analysis of engine oil samples with the determination of the kinematic viscosity at $40^{\circ} \mathrm{C}$ and at $100^{\circ} \mathrm{C}$. It also includes flash point, base number, water content, and the assessment of the contamination of the oil in question.

The fifth level of the technique involves spectral analysis of the engine oil in order to determine the presence of metals.

\section{Research result}

The following engine oils were tested on BelAZ dump trucks at certain operating times: Valvoline SAE 15W-40, which is used on Cummins QSM11-C and Cummins QSX-15-C345 diesels; LOTOS SL/CF SAE 15W-40, which is used on YaMZ-240M2 and YAMZ-240PM2 diesels.

In the controlled modification of the engine oil the drug "NanoKOR-F"was used. At the first level the autopreparation meets the requirements of regulatory documents both in appearance and in the density and content of ultrafine particles of diamond, iron and polytetrafluoroethylene, as well as in the content of the base of the preparation. The appearance of ultrafine particles is shown in Fig. 1. 


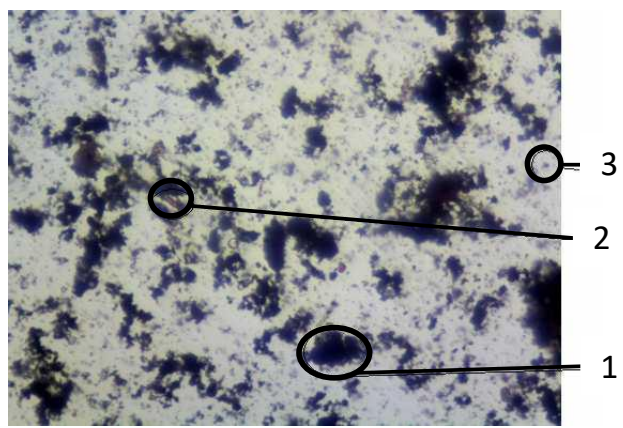

Fig. 1. Micrographs (x350) of ultrafine particles in the field of a microscope: 1 - modified polytetrafluoroethylene; 2 - iron; 3 - diamonds.

The second level of the method of controlled modification of engine oil revealed the following: only about $18 \%$ out of the total number of engines require immediate intervention in its systems. That is, maintenance work can be delayed for some time, while reducing the annual labor intensity of work without losing the resource of mining dump truck engines. It is possible to achieve an extension of the resource and efficiency in some cases. The third level allowed us to obtain enough information to establish a pre-trial detention. Thus, in the table 1 and 2 there are the characteristics of the drip sample of the studied engine oils.

Table 1. Characteristics of the drip sample of engine oil of mining dump truck engines

\begin{tabular}{|c|c|c|c|c|c|c|c|c|c|c|c|c|}
\hline \multirow{4}{*}{ Drip sample area } & \multicolumn{12}{|c|}{ Brand of engine oil } \\
\hline & \multicolumn{6}{|c|}{$\begin{array}{l}\text { SAE 15W-40 (Cummins QSM11- } \\
\text { C) }\end{array}$} & \multicolumn{6}{|c|}{$\begin{array}{c}\text { SAE 15W-40 (Cummins QSX-15 } \\
\text { C345) }\end{array}$} \\
\hline & \multicolumn{12}{|c|}{ Operating time, moto-hour } \\
\hline & 0 & 100 & 200 & 300 & 400 & 500 & 0 & 100 & 200 & 300 & 400 & 500 \\
\hline Core & - & - & - & - & + & + & - & - & - & - & + & + \\
\hline Edge zone & - & - & + & + & + & + & - & + & + & + & + & + \\
\hline Diffusion & - & + & + & + & + & + & - & + & + & + & + & + \\
\hline \multirow[t]{5}{*}{ Pure Oil } & + & - & - & - & - & + & + & - & - & - & + & + \\
\hline & \multicolumn{12}{|c|}{ Brand of engine oil } \\
\hline & \multicolumn{6}{|c|}{ SAE 15W-40 (YAMZ -240M2) } & \multicolumn{6}{|c|}{ SAE 15W-40 (YAMZ -240PM2) } \\
\hline & \multicolumn{12}{|c|}{ Operating time, moto-hour } \\
\hline & 0 & 100 & 200 & 300 & 400 & 500 & 0 & 100 & 200 & 300 & 400 & 500 \\
\hline Core & - & - & - & - & + & + & - & - & - & - & + & + \\
\hline Edge zone & - & + & + & + & + & + & - & + & + & + & + & + \\
\hline Diffusion & - & + & + & + & + & + & - & + & + & + & + & + \\
\hline Pure Oil & + & - & - & - & - & + & + & - & - & - & + & + \\
\hline
\end{tabular}

Table 1 shows that the edge zone appears at $100 \ldots 200$ operating hours of dump truck engines. This indicates the presence of wearing signs and the appearing of abrasive particles during the basic operation of the engine oil.

The data given in Table 2 indicate that the edge zone appears at the operating time of $300 \ldots 400$ hours of driving time with a controlled modification of the engine oil. This appearance occurs much later in comparison with the basic version of engine oil operation. In this regard, it can be argued that the rate of wear of the engine parts of dump trucks is lower, and the permissible service life of the oil, in this case, increases by $33 \ldots 50 \%$. The decrease in the properties of motor oils is slower, as evidenced by the later appearance of the core and the diffusion zone of pure oil on drip samples.

The operating conditions and the presence of small fractions of abrasive rocks have a significant impact on the degradation of the oil. 
Table 2. Characteristics of the drip sample of the engine oil of mining dump truck engines under controlled modification of the engine oil

\begin{tabular}{|c|c|c|c|c|c|c|c|c|c|c|c|c|}
\hline \multirow{4}{*}{ Drip sample area } & \multicolumn{12}{|c|}{ Brand of engine oil } \\
\hline & \multicolumn{6}{|c|}{$\begin{array}{c}\text { SAE } 15 W-40 \text { (Cummins QSM11- } \\
\text { C) }\end{array}$} & \multicolumn{6}{|c|}{$\begin{array}{c}\text { SAE 15W-40 (Cummins QSX-15- } \\
\text { C345) }\end{array}$} \\
\hline & \multicolumn{12}{|c|}{ Operating time, moto-hour } \\
\hline & 0 & 100 & 200 & 300 & 400 & 500 & 0 & 100 & 200 & 300 & 400 & 500 \\
\hline Core & - & - & - & - & - & + & - & - & - & - & - & + \\
\hline Edge zone & - & - & - & + & + & + & - & - & - & + & + & + \\
\hline Diffusion & - & + & + & + & + & + & - & + & + & + & + & + \\
\hline \multirow[t]{5}{*}{ Pure Oil } & + & - & - & - & - & - & + & - & - & - & - & - \\
\hline & \multicolumn{12}{|c|}{ Brand of engine oil } \\
\hline & & $15 \mathrm{~V}$ & 40() & $\mathrm{AMZ}$ & -240 & M2) & SA & $5 \mathrm{~W}-4$ & $(\mathrm{YA}$ & $\mathrm{MZ}-2$ & $240 \mathrm{PI}$ & M2) \\
\hline & \multicolumn{12}{|c|}{ Operating time, moto-hour } \\
\hline & 0 & 100 & 200 & 300 & 400 & 500 & 0 & 100 & 200 & 300 & 400 & 500 \\
\hline Core & - & - & - & - & - & + & - & - & - & - & - & + \\
\hline Ede Zone & - & - & - & + & + & + & - & - & - & + & + & + \\
\hline Diffusion & - & + & + & + & + & + & - & + & + & + & + & + \\
\hline Pure Oil & + & - & - & - & - & - & + & - & - & - & - & + \\
\hline
\end{tabular}

The fourth level of controlled modification of engine oil in the operation of mining dump truck engines showed the results shown in Tables 3 and 4.

Table 3. Results of chemical analysis of the engine oil of mining dump truck engines based on the basic version

\begin{tabular}{|c|c|c|c|c|c|c|c|c|c|c|c|c|}
\hline \multirow{4}{*}{ Measured parameters } & \multicolumn{12}{|c|}{ Brand of engine oil } \\
\hline & \multicolumn{6}{|c|}{ SAE 15W-40 (YAMZ -240M2) } & \multirow{2}{*}{\multicolumn{6}{|c|}{ SAE $15 \mathrm{~W}-40$}} \\
\hline & \multicolumn{11}{|c|}{ Operating time, moto-hour } & \\
\hline & 0 & 100 & 200 & 300 & 400 & 500 & 0 & 100 & 200 & 300 & 400 & 500 \\
\hline Viscosity, $\times 10^{-6}, \eta \mathrm{M}^{2} / \mathrm{c}$ & $\begin{array}{l}n \\
0 \\
0 \\
\hat{n} \\
a\end{array}$ & $\begin{array}{l}n \\
0 \\
0 \\
\hat{0} \\
\sigma\end{array}$ & $\begin{array}{l}n \\
\hat{n} \\
\hat{n} \\
\alpha\end{array}$ & $\begin{array}{l}n \\
0 \\
0 \\
\infty \\
0 \\
0\end{array}$ & $\begin{array}{l}n \\
0 \\
0 \\
\infty \\
0 \\
0\end{array}$ & $\begin{array}{l}n \\
0 \\
\hat{H} \\
a\end{array}$ & $\begin{array}{l}n \\
\hat{0} \\
\hat{1} \\
\alpha\end{array}$ & $\begin{array}{l}n \\
0 \\
0 \\
\infty \\
0\end{array}$ & $\begin{array}{l}n \\
0 \\
01 \\
\infty \\
0 \\
0\end{array}$ & $\begin{array}{l}n \\
\hat{n} \\
\stackrel{1}{n} \\
a\end{array}$ & $\begin{array}{l}n \\
0 \\
+1 \\
a \\
a\end{array}$ & $\begin{array}{l}n \\
0 \\
0 \\
0 \\
0 \\
0\end{array}$ \\
\hline Flash point $t_{c n}, \mathrm{~K}$ & 497 & 492 & 488 & 475 & 470 & 460 & 497 & 490 & 475 & 471 & 463 & 460 \\
\hline Base number, $k \mathrm{MgKOH} / \mathrm{g}$ & 9,0 & 8,7 & 8,7 & 8,4 & 8,1 & 7,8 & 9,0 & 8,9 & 8,8 & 8,8 & 8,7 & 8,2 \\
\hline Water content, $\%$ & 0,10 & 0,11 & 0,15 & 0,17 & 0,18 & 0,22 & 0,10 & 0,12 & 0,17 & 0,20 & 0,21 & 0,23 \\
\hline Density, $\mathrm{Kg} / \mathrm{M}^{3} \times 10^{3}$ & 0,91 & 0,91 & 0,91 & 0,93 & 0,94 & 0,95 & 0,91 & 0,90 & 0,91 & 0,92 & 0,95 & 0,95 \\
\hline Pollution level, \% & 0,12 & 0,15 & 0,17 & 0,18 & 0,22 & 0,27 & 0,12 & 0,17 & 0,17 & 0,19 & 0,24 & 0,27 \\
\hline
\end{tabular}

The obtained results give a fairly reliable picture of the change in the properties of engine oil, depending on the operating time of heavy-duty vehicle engines. Thus, the engine oil SAE $15 \mathrm{~W}-40$ (YAMZ-240M2) has a viscosity that decreases from $9.9 \pm 0.5 \times 10^{-6}$ to $9.7 \pm 0.5 \times$ $10^{-6} \mathrm{~m}^{2} / \mathrm{s}$. The viscosity changes almost similarly and insignificantly during the entire service life. It decreases from $9,9 \pm 0,5 \times 10^{-6}\left(10,0 \pm 0,5 \times 10^{-6}-\right.$ maximum) up to $9.8 \pm 0.5 \times 10^{-6}$ $\mathrm{m}^{2} / \mathrm{s}$ with controlled modification of the engine oil. The available dynamics of the water content proves that before the oil change with an equal operating time (500 moto-hours) the concentration did not exceed the permissible level with controlled modification of the engine oil. It was still less $-0.19 \%$ vs. $0.22 \%$. As a result, the obtained resource before oil change, which coincides with the recommended one, is satisfactory.

Other indicators presented in Tables 3 and 4 showed better dynamics of changes in the controlled modification of the engine oil than in the basic version. At the same time, the flash point was $481 \ldots 496 \mathrm{~K}$ with controlled modification and $460 \ldots 497 \mathrm{~K}$ was in the basic version. The base number varied from 8.4...9.1 in the controlled modification and 7.8...9.0 in the basic version. The density increased in the range of $910 \ldots 920$ in the controlled modification and 
$910 \ldots 950 \mathrm{~kg} / \mathrm{m}^{3}$ in the basic version. The contamination was $0.12 \ldots 0.20 \%$ in the controlled modification and $0.12 \ldots 0.27 \%$ in the basic version.

Table 4. Results of chemical analysis during controlled modification of the engine oil of mining dump truck engines based on.

\begin{tabular}{|c|c|c|c|c|c|c|c|c|c|c|c|c|}
\hline \multirow{4}{*}{$\begin{array}{l}\text { Measured } \\
\text { parameters }\end{array}$} & \multicolumn{12}{|c|}{ Brand of engine oil } \\
\hline & \multicolumn{6}{|c|}{ SAE 15W-40 (YAMZ-240M2) } & \multicolumn{6}{|c|}{ SAE 15W-40 (YAMZ -240PM2) } \\
\hline & \multicolumn{12}{|c|}{ Operating time, moto-hour } \\
\hline & 0 & 100 & 200 & 300 & 400 & 500 & 0 & 100 & 200 & 300 & 400 & 500 \\
\hline $\begin{array}{c}\text { Viscosity, } \times 10^{-6}, \eta, \\
\mathrm{M}^{2} / \mathrm{c}\end{array}$ & $\begin{array}{l}n \\
0 \\
\text { 11 } \\
\text { aे }\end{array}$ & $\begin{array}{l}n \\
0 \\
1 \\
0 \\
0\end{array}$ & $\begin{array}{l}n \\
0 \\
\text { मn } \\
\text { aे }\end{array}$ & $\begin{array}{l}n \\
\hat{1} \\
\text { aे } \\
\sigma\end{array}$ & $\begin{array}{l}n \\
0 \\
+1 \\
\infty \\
0\end{array}$ & $\begin{array}{l}n \\
0 \\
\infty \\
\infty \\
\sigma\end{array}$ & $\begin{array}{l}n \\
0 \\
0 \\
\text { aे }\end{array}$ & $\begin{array}{l}n \\
0 \\
0 \\
\infty \\
\sigma\end{array}$ & $\begin{array}{l}n \\
0 \\
0 \\
\infty \\
0\end{array}$ & $\begin{array}{l}n \\
0 \\
0 \\
\infty \\
\sigma\end{array}$ & $\begin{array}{l}n \\
0 \\
0 \\
\infty \\
0\end{array}$ & $\begin{array}{l}n \\
0 \\
0 \\
\infty \\
\sigma\end{array}$ \\
\hline Flash point, $t_{c n}, \mathrm{~K}$ & 496 & 491 & 492 & 485 & 483 & 481 & 496 & 482 & 481 & 481 & 473 & 469 \\
\hline $\begin{array}{l}\text { Base number } k \text {, } \\
\text { мгКОН/Г }\end{array}$ & 9,1 & 9,0 & 8,9 & 8,8 & 8,8 & 8,4 & 9,0 & 8,2 & 8,0 & 7,9 & 7,8 & 7,8 \\
\hline Water content, \% & 0,10 & 0,11 & 0,12 & 0,14 & 0,15 & 0,19 & 0,10 & 0,11 & 0,11 & 0,12 & 0,13 & 0,15 \\
\hline Density, кг $/ \mathrm{M}^{3} \times 10^{3}$ & 0,91 & 0,91 & 0,91 & 0,92 & 0,92 & 0,92 & 0,91 & 0,91 & 0,91 & 0,91 & 0,92 & 0,92 \\
\hline Pollution level, \% & 0,12 & 0,14 & 0,15 & 0,16 & 0,19 & 0,20 & 0,12 & 0,15 & 0,16 & 0,18 & 0,20 & 0,20 \\
\hline
\end{tabular}

The second group of engines with engine oil SAE 15W-40 (YAMZ-240PM2) had a similar dynamics of changes in viscosity, water concentration, density, alkaline number, flash point, and contamination. The results of the conducted chemical analysis show that with such dynamics of changes in the concentration of water in the engine oil the prohibition of operation or dewatering of engine oils should be carried out with the basic version already at the operating time of up to 400 moto-hours, and with controlled modification of the engine oil after 500 moto-hours. The increase in the operating time for controlled modification of engine oil is up to $30 \%$.

The article does not present the results of operational studies of engine oils of Cummins QSM11-C and Cummins QSX-15-C345 engines, since similar data were obtained as for YaMZ engines. At the same time, it is worth noting that with controlled modification of engine oil, the change in its properties in the direction of deterioration is much slower than with the basic version.

Chemical analysis of the specific parameters of the engine oil allows to assert a lower dynamics of their changes in the controlled modification of the engine oil than in the basic version. In particular, this is reflected in a density increase with a deterioration in viscosity characteristics, loss of stability, an increase in pollution, consumption of alkaline properties, and an increase in water concentration.

The fifth level allowed us to obtain the results of operational studies using spectral analysis. The results of changes in the concentration of chemical elements in the engine oil of Cummins QSM11-C engines with the basic version and with controlled modification of the engine oil are shown in Fig. 2.

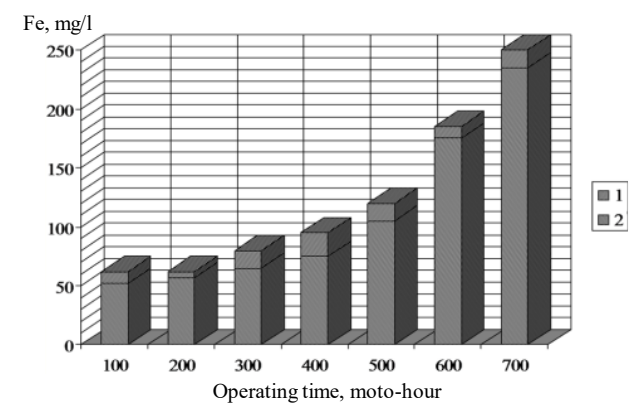


a)

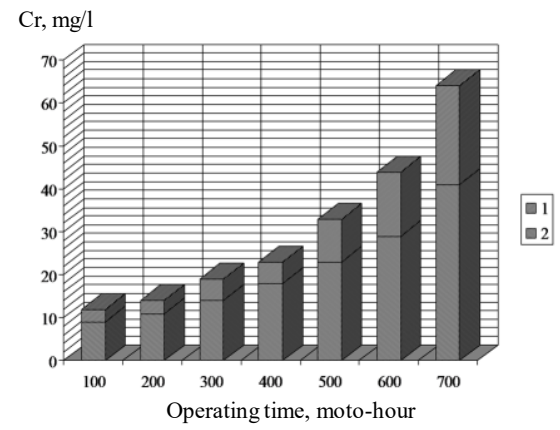

b)

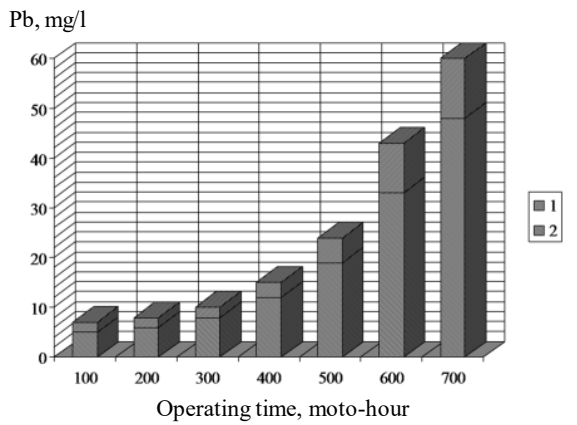

c)

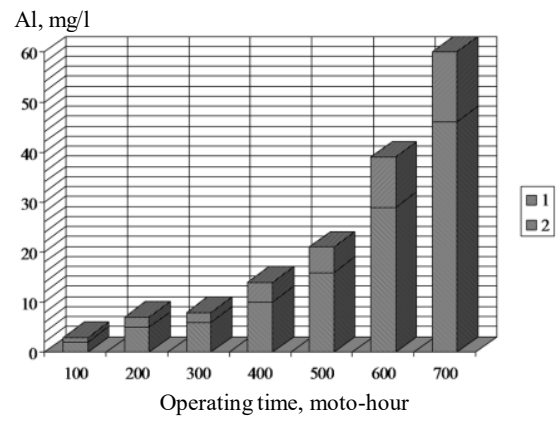

d)

Fig. 2. Changes in the concentration of chemical elements in the engine oil of Cummins QSM11-C engines in the basic version (1) and in the controlled modification of the engine oil (2): $a-$ iron; $b-$ chromium; c-lead; d-aluminum.

The given dependences (Fig. 2) of the concentrations of wear products in the engine oil in the case of controlled modification of the engine oil indicate that the oil change can be performed at least 150 moto-hours later than in the basic version. The concentrations of other elements, indicators of wear of the rubbing pairs of YaMZ-240M2 engines, at operating time up to 700 moto-hours do not exceed the permissible ones, so they are not given.

The change in the concentration of chemical elements in the engine oil of the YaMZ$240 \mathrm{M} 2$ engines in the basic version and in the controlled modification of the engine oil is shown in Fig. 3. 


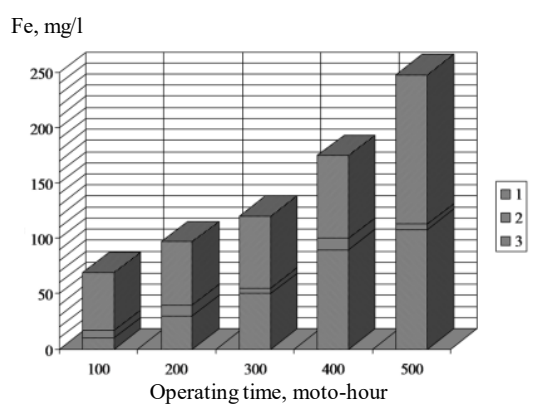

a)

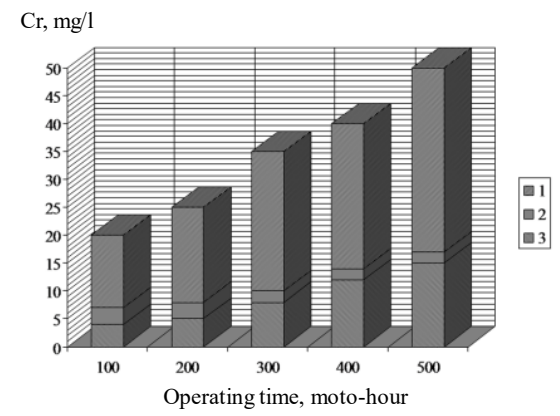

b)

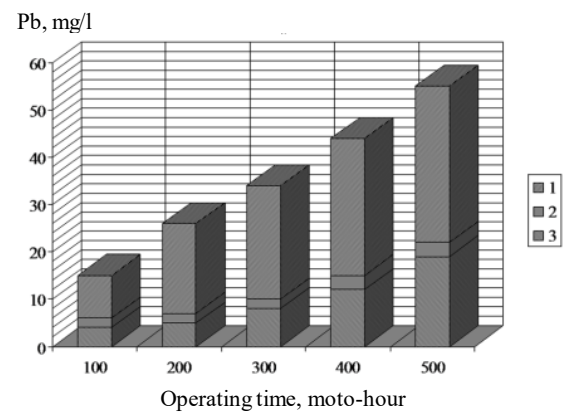

c)

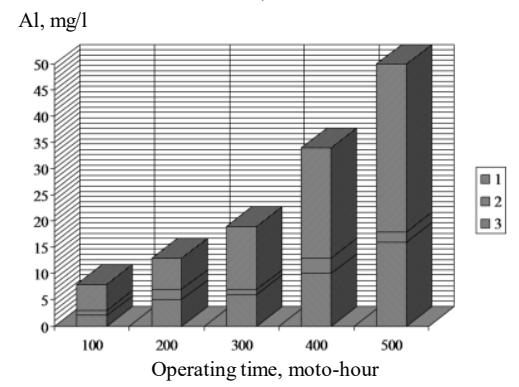

d)

Fig. 3. Changes in the concentration of chemical elements in the engine oil of YaMZ-240M2 engines with the basic version (1) and with controlled modification of the engine oil (2) and with the addition of an autopreparation from the beginning of operation (3): $a$ - iron; $b$ - chromium; $c$ - lead; $d$ - aluminum.

Fig. 3 shows the diagrams for elements which concentrations exceed the standard data. The concentrations of other elements during the operating time of the YaMZ-240M2 engines 
in 500 moto-hours do not exceed the permissible ones, so it would be inappropriate to give them.

The obtained data indicate that during the operation of the YaMZ-240M2 engines with controlled modification of the engine oil and an operating time of 500 moto-hours the concentration of wear product elements in the engine oil does not exceed: iron, chromium, lead, aluminum. That is, the replacement of engine oil must be carried out later. The latter indicates the feasibility of using an autopreparation to improve the performance of heavyduty vehicle engines and the use of a controlled modification of engine oil.

\section{Conclusion}

The results of operational studies of the performance of heavy-duty car engines showed, when the technique of controlled modification of engine oil is used, using the "NanoKOR$\mathrm{F}^{\prime}$ autopreparation allows you to extend the service life of engine oil by $30 \ldots 50 \%$ longer compared to the basic version. In turn, this allows us to claim an increase in the resource of the engines of quarry dump trucks by the same amount.

\section{References}

1. L. I. Andreeva. IOP Conf. Ser.: Mater. Sci. Eng., ICMTME, 2020, 044044 (2019)

2. E. Kuzin, V. Bakin, D. Dubinkin. E3S Web of Conferences 41, 03020 (2018)

3. Z. W. Guo, C. Q. Yuan, X. Q. Bai, et al. Chin. J. Mech. Eng. 31, 52 (2018)

4. E. Kuzin, B. Gerike, Y. Drozdenko et al. IOP Conf. Ser.: Mater. Sci. Eng., 253, 012013 (2017)

5. X. Xiao, J. Hu, D.H. Charych, M. Salmeron, Langmuir 1, 77, 235 (1996)

6. M. Masuko, H. Miyamoto, A. Suzuki. Trib. Intern., 40, 1587 (2007)

7. Z. Tang, S. Li. Curr. Opinion in Solid State and Mat. Sci., 18, 119 (2014)

8. A. Nehal, N. Amal. Lubricating Oil Additives. 10, 5772/22923 (2011)

9. S. Jahanmir, M. Beltzer. Trans ASME J. Tribol 108, 109 (1986)

10. V. L. Lashkhi, St. Leimeter, G. I. Shor, M. I. Fal'kovich. Chemistry and Technology of Fuels and Oils, 5 (37), 372 (2001)

11. G. I. Shor, I. G. Fuks. Chemistry and Technology of Fuels and Oils, 4(484), 44 (1997)

12. S. A. Mammadov, S. I. Mammadova, N. P. Ladokhina et al. European journal of analytical and applied chemistry, 1, 13 (2016)

13. V. N. Demenkov. Chemistry and Technology of Fuels and Oils, 33(4), 207 (1997)

14. M. Mamaeva, E. Kuzin E. MATEC Web of Conferences 297, 03006 (2019)

15. R. Ranjan, S. Ghosh and M. Kumar, IOP Conf. Ser.: Mater. Sci. Eng., 377, 012216 (2018)

16. B. Gerike, I. Panachev, E. Kuzin, E3S Web of Conferences, 15, 03008 (2017) 